\title{
The Application of Augmented Reality in University
}

\author{
Yue Zhao ${ }^{1, a^{*}}$ and Chao Chen ${ }^{1, b}$ \\ ${ }^{1}$ College of Information Science and Technology, Bohai University, Jinzhou 121013, China \\ azy_ky7777@126.com, ${ }^{\mathrm{b}} \mathrm{chch56@126.com}$
}

Keywords: Augmented reality; Classroom teaching; Interactivity; Application

\begin{abstract}
As a research hotspot in recent years, augmented reality technology has been favored in various fields. This paper introduces the concept of augmented reality technology and the research status quo at home and abroad, and introduces the working principle of Augmented Reality. And further explores its advantages in classroom teaching. Finally, the future development of education in the field of education is forecasted.
\end{abstract}

\section{Introduction}

Augmented reality (Augmented Reality, referred to as AR), is through the computer system will be virtual information superimposed on the real scene, in order to achieve the enhanced technology of reality [1-2]. In recent years, augmented reality technology has been rapid development in medical, industrial maintenance, television, entertainment, monuments, education, and many other areas to be applied[3-8]. From the current development situation can be seen, due to enhance the reality of interactive technology and other characteristics of its application in the field of education will form a new interactive platform for teaching, through technical means to achieve educational innovation. This paper will discuss the application of augmented reality technology in the teaching of higher education.

\section{Augmented Reality Introduction}

Augmented reality technology is an emerging technology based on virtual technology. It integrates computer graphics technology, computer vision technology, sensor technology and human-computer interaction technology in a variety of disciplines [9-10]. Augmented reality technology research began in the 1960s, 1965, Harvard University professor Ivan Sutherland and his colleagues to develop the world's first augmented reality prototype system. Real-time interaction, three-dimensional registration and so on. Since 1998, there have been a number of academic discussions related to augmented reality techniques, such as the International Augmented Reality Working Conference (IWAR), the International Augmented Reality Workshop (ISAR), etc. . At present, there are many academic research institutions engaged in augmented reality technology at home and abroad. Abroad, such as the United States, Massachusetts Institute of Technology, Columbia University, University of Toronto, Canada. There are Beijing Institute of Technology, Beijing University of Aeronautics and Astronautics, National Defense University, Zhejiang University.

At present, augmented reality technology has been applied in the field of education, such as the "Magic Book System" developed by the University of Washington and the Sony Computer Laboratory; Woods E and Billinghurst M developed by the New York University of Canterbury Human Machine Interaction Laboratory, The user can learn the knowledge of the galaxy through the interaction defined by the system.

\section{Working Principle of Augmented Reality}

System Application Model of Augmented Reality System Application Model. According to the augmented reality system application shows the different ways, can be divided into three modes: 
(1) Based on the helmet-mounted display (HMD) optical synthesis. The user through the helmet on the translucent composite screen directly observe the real scene, and projected onto the composite screen, thus seeing the actual situation of the combination. As shown in Fig. 1.

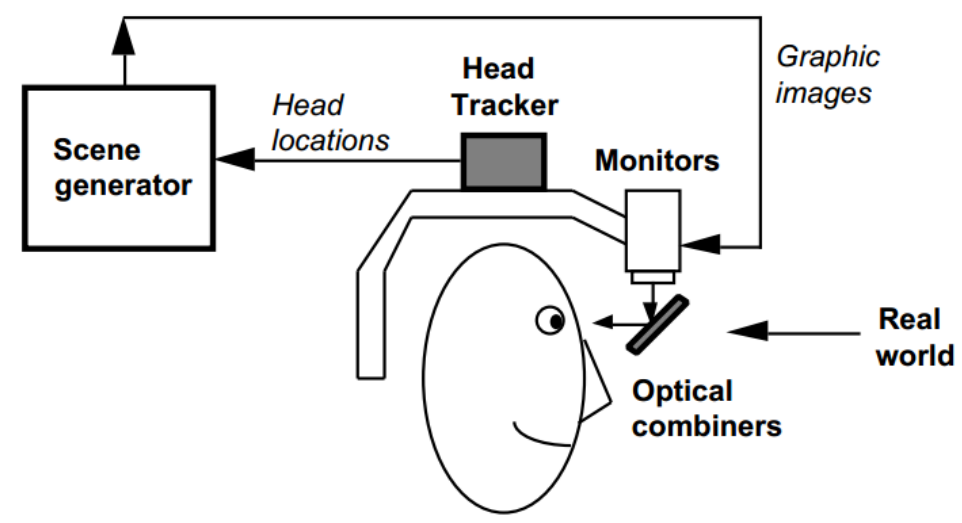

Figure 1. Optical see-through HMD conceptual diagram

(2) Based on the helmet-mounted display (HMD) image synthesis. By combining the images captured by the head-mounted camera with the virtual graphics, the synthesized image is displayed on an opaque display. As shown in Fig. 2.

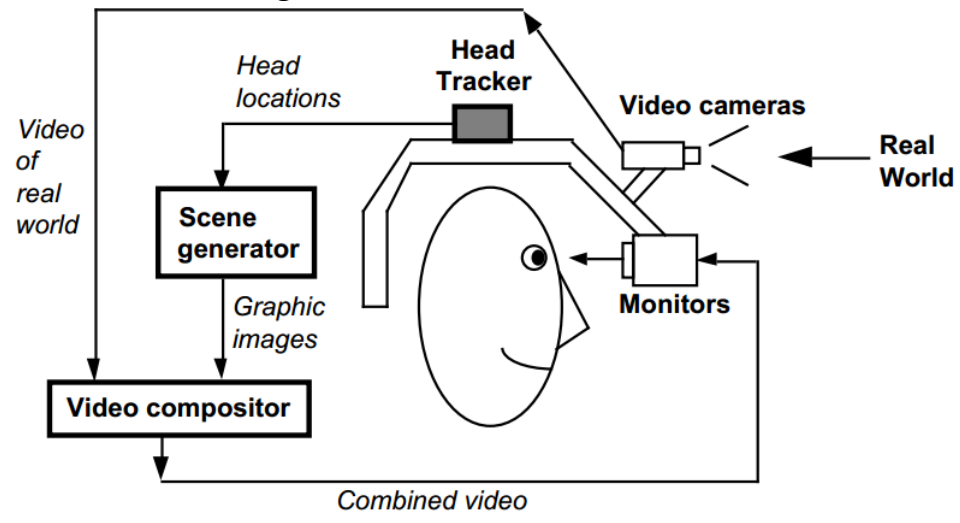

Figure 2. Video see-through HMD conceptual diagram

(3) Display-based rendering. In this way the image display principle and the former two kinds of the same, but the virtual part of the scene and the real part of the display through the computer, the camera and the observation screen in a separate state, the user does not need to wear HM.

Augmented Reality System Based on Artificial Markers. Tracking technology is one of the key technologies to restrict AR application and development. In tracking technology, AR mainly through the use of GPS tracking, marker-based tracking and tracking based on nature (no marker tracking) 3 stages. Marker-based tracking greatly reduces computational requirements and computational complexity by placing Premark. The purpose of artificial signs is to provide mapping information to virtual objects. The advantage of using artificial signs is that the operator can interact with the virtual objects in real time. Firstly, the binary image is processed by fixed threshold segmentation method according to the light condition, and then the polygonal approximation is obtained by contour tracking. The quadrangle is obtained and the quadrangle with too small angle is discarded. Then, the image of the middle part of the marker is Template library with the same code template image template matching to determine the marker. Finally, according to the location of the marker will be pre-made virtual objects added to the real scene of the video stream. The user can interact with the AR system by moving the location of the marker.

Fig. 3 shows an augmented reality application based on artificial markers 


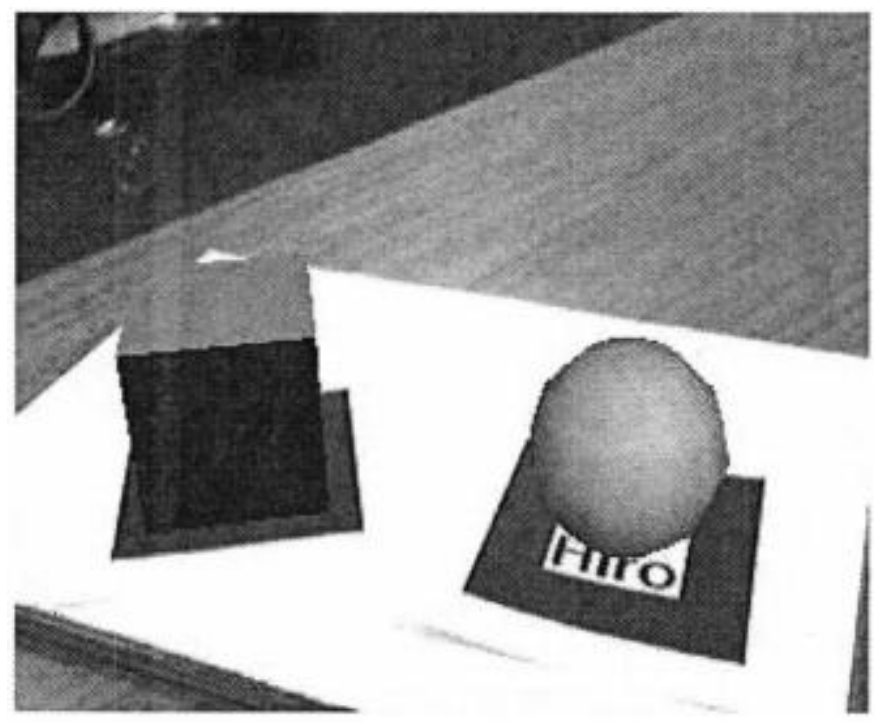

Figure 3. An augmented reality application based on artificial markers

Three-Dimensional Registration and Coordinate Transformation. Three-dimensional registration is the virtual object and the real scene in three-dimensional location of the consistency, that is, integration in space. Three-dimensional registration process involves virtual space, real space, projection space, the projection plane of the four spatial position of the transformation, as shown in Figure 3. In the technical transformation of the coordinate system by way of matrix transformation.

\section{The Status Quo of Classroom Teaching in Traditional Colleges and Universities}

The main form of classroom teaching in colleges and universities is the mode of teaching and listening. In this model, the teacher imparts knowledge is the process of simple one-way information transfer, impart knowledge to students. Even in the classroom by adding students to participate in the link, cannot be vivid to the knowledge, the image of the teaching. In most cases, for abstract knowledge, teachers can only complete the whole process of classroom teaching, students do not participate in the opportunity. This situation led to a boring classroom atmosphere, the rigid content of teaching, difficult to understand, so that students learn less enthusiasm, limiting thinking.

\section{The Application of Augmented Reality Technology in the Classroom Teaching}

Teaching Content Intuitive, Image, Novel. A lot of knowledge of classroom teaching is more abstract, the use of augmented reality technology can be more intuitive to students, vividly display teaching information, through vivid images, animation and other forms of intuitive description and presentation of subject knowledge, (intuitive teaching principles In the classroom teaching the specific use of) through the computer monitor, projection and other related information presented to the students, to provide students with sensory stimulation to attract students' learning attention, to the students a great learning fun but also inspired the Students' learning motivation. Augmented reality technology to make up for the lack of traditional teaching at the same time, strengthen the classroom teaching.

To Help Students Develop a Variety of Abilities. The learning environment of augmented reality technology is three-dimensional. Students experience the knowledge in three-dimensional space by color, shape and sense of space. In three-dimensional space, students can cultivate the three-dimensional sense of space, and make many abstract teaching content (such as magnetic sense line, molecular motion, etc.) in three-dimensional space environment easier to understand.

The Learning Environment Is Interactive. In the process of augmented reality teaching, students can be provided with an interactive learning environment close to nature. This virtual learning environment provides students with a rich emotional experience. In this interactive 
learning environment, students can experience what they have learned in order to learn the form of hands-on knowledge, deepen the understanding of knowledge at the same time strengthen the memory, and can improve the students hands-on ability and self-learning ability.

\section{Conclusions}

As a research hotspot in recent years, augmented reality technology has begun to be applied in various fields. While the majority of augmented reality applications are still in the initial stages and time-consuming to apply to everyday life, augmented reality technology will become a part of our lives in the near future. With the development of augmented reality technology is mature, augmented reality technology in the field of education and teaching applications will become a trend. Especially in the three-dimensional books, AR education games, operational skills training will be a comprehensive application and development. The application of augmented reality technology to college classroom teaching is of great significance to the innovation of classroom teaching mode and the development of education.

\section{References}

[1] R.T. Azuma: Tele-operators and Virtual Environments, Vol. 6(1997) No.4, p.355.

[2] R. Azuma, Y. Baillot, R. Behringer, S. Feiner, S. Julier, and B. MacIntyre: IEEE Computer Graphics and Applications, Vol. 21(2001) No.6, p.34.

[3] S. Feiner, B. Macintyre and D. Seligmann: Communications of the ACM, Vol.36 (1993) No.7, p.53.

[4] G Papagiannkis, S schertenleib and B. O'kennedy: Computer Animation and Uirtual Worlds, Vol. 16(2005) No.1, p.11.

[5] Information on http://www.n-show.com.cn

[6] M. Bajura, H. Fuchs and R. Ohbuchi: Computer Graphics (ACM), Vol.26 (1992) No.2, p.203.

[7] Information on https://itunes.apple.com/app/id794481981

[8] Information on http://finance.qq.com/a/20120405/004010.htm

[9] C.E.Hughes, C.B. Stapleton and D. E. Hughes: IEEE Computer Graphics and Applications, Vol.25(2005) No.6,p.24

[10]Information on http://www.idemployee.id.tue.nl/g.w.m.rauterberg/presentations/hci-history/ tsld096.htm 